\title{
A questão feminina: importância estratégica das mulheres para a regulação da população brasileira (1930-1945)*
}

\author{
Natascha Stefania Carvalho De Ostos ${ }^{* * *}$
}

\section{Resumo}

Este artigo propõe analisar como as mulheres no Brasil da Era Vargas foram consideradas, por diversos grupos sociais e pelo poder instituído, como instrumento privilegiado para a transformação do quadro populacional do país. A defesa pública daquilo que muitos consideravam como funções femininas adquiriu nova perspectiva: cuidar do lar, desempenhar a maternidade, zelar pelo bem estar do outro, constituíam atividades que foram redimensionadas, no quadro social e político da época, como atribuições essenciais para a construção de uma população brasileira saudável, disciplinada e operosa.

Palavras-chave: Era Vargas, População, Mulheres.

\footnotetext{
* Recebido para publicação em 05 de abril de 2010, aceito em 17 de agosto de 2011. Este artigo originou-se em minha dissertação de mestrado defendida no Programa de Pós-Graduação em História da Universidade Federal de Minas Gerais - UFMG, em 2009, sob o título: Terra Adorada, Mãe Gentil: representações do feminino e da natureza no Brasil da Era Vargas (1930-1945). Agradeço as inestimáveis contribuições de Dra. Regina Horta Duarte, orientadora, professora titular do Departamento de História da UFMG, e da banca examinadora, composta pelas professoras Dra. Eliana Regina de Freitas Dutra (UFMG) e Dra. Regina Beatriz Guimarães Neto (UFPE). Agradeço ainda à FAPEMIG, cujo suporte financeiro tornou possível esta pesquisa, e ao grupo de pesquisa Coleção Brasiliana - Escritos e Leituras da Nação, pelos frutíferos debates.

** Doutoranda no Programa de Pós-Graduação em História da Universidade Federal de Minas Gerais - UFMG. Bolsista/Apoio Coordenação de Aperfeiçoamento de Pessoal de Nível Superior - CAPES.

nataschaostos@hotmail.com
}

cadernos pagu (39), julho-dezembro de 2012:313-343. 
A questão feminina...

The Female Issue: Women's Strategic Importance for the Regulation of the Brazilian Population (1930-1945)

\begin{abstract}
This study examines how women in Brazil's Vargas Age were considered, by various social groups and established power, as a privileged instrument for the transformation of the country's population. The public defense of what many regarded as female roles, acquired a new perspective: taking care of home, becoming mothers, ensuring the welfare of others, were activities which were remodeled, in the social and political context of the time, as essential tasks for building a healthy, disciplined, and industrious Brazilian population
\end{abstract}

Key Words: Vargas Age, Population, Women. 


\section{Introdução}

Ao longo das primeiras décadas do século $\mathrm{XX}$, todas as controvérsias, propostas e ideias relacionadas com a discussão do papel social $e$ das condições de vida das mulheres brasileiras delimitaram o que então se convencionou chamar de a questão feminina. Naquele momento, o país se via, cada vez mais, exposto a um estilo de vida moderno, que acelerava o ritmo das mudanças sociais, principalmente nas regióes urbanas do centro-sul do Brasil. No que toca à população feminina, o meio urbano oferecia às mulheres ${ }^{1}$ a possibilidade de conhecer outras formas de convivência, para além daquelas experimentadas no espaço doméstico e nas relações familiares, já que as cidades abrigavam diversos locais de diversão, estabelecimentos de ensino e postos de trabalho, onde notícias e novidades circulavam rapidamente, através das mais variadas publicações impressas e do burburinho próprio do ambiente citadino. A vida das mulheres também se viu afetada pelo avanço contínuo da economia de mercado no Brasil, que desvalorizava a produção doméstica, levando à queda do valor econômico do trabalho feminino realizado em casa. As crescentes necessidades de consumo, que foram então criadas, diminuíam o poder aquisitivo das camadas pobres, já enfraquecidas pelos baixos salários e pela alta taxa de inflação que vigorava nas primeiras décadas do século XX. Paralelamente a esses fenômenos, o país se industrializava, e certos setores

\footnotetext{
1 Estamos analisando, neste artigo, uma série de discursos que, em sua maioria, compreendia a população feminina como um conjunto dotado de certa uniformidade; as mulheres eram percebidas como um grupo relativamente indistinto em razão de compartilharem certas características anatômicas $e$ fisiológicas que determinariam, não apenas sua aparência e o funcionamento de seus corpos, como também suas qualidades psíquicas, seu papel social e suas habilidades "inatas". O fato de lidarmos com discursos que essencializavam as mulheres, e de estarmos interessados na construção histórica de sentidos a respeito dessa categoria, não implica numa adesão ingênua aos pressupostos que constituem esse marcador de identidade.
} 
A questão feminina...

da economia demandavam o emprego preferencial de mão de obra feminina.

Independentemente da sua condição social, todas as mulheres encontravam limites legais ao exercício de sua liberdade. Pelo Código Civil de 1916, o marido era o "chefe da sociedade conjugal" encarregado de administrar os bens do casal, fixar o domicílio familiar e prover o sustento dos seus. O divórcio não era permitido e o casamento só era passível de anulação em casos extremos. A mulher casada era considerada como relativamente incapaz para exercer certos atos legais, não podendo trabalhar fora de casa sem autorização prévia do marido, exercer papel de tutora ou curadora, litigar em juízo cível ou criminal e contrair obrigações; somente em caso de ausência ou impedimento do esposo, ela tinha o direito de exercer o pátrio poder sobre os filhos (Código Civil, 1916: artigos 6; 233 a 380) ${ }^{2}$.

Contudo, as transformações econômicas, políticas e culturais do início do século XX franqueavam às mulheres (principalmente para as que viviam no meio urbano) maior participação no mundo público, dando ensejo, por exemplo, à formação de organizações feministas ${ }^{3}$ que lutavam em prol de melhores condições de vida para as mulheres. A maioria dessas associações assumiu a reivindicação do direito de votar como ponta de lança para a elaboração de outras demandas; por essa razão, mesmo com a promulgação de um novo Código Eleitoral, em 1932 (momento em que as brasileiras conquistaram o voto), não cessou a discussão em torno dos direitos e dos deveres que caberiam às mulheres, sempre com grande destaque na imprensa nacional, pois se intuía que, na esteira desse primeiro avanço, outras transformações poderiam ocorrer.

\footnotetext{
2 Todos os dispositivos legais citados estão disponíveis em <www.senado.gov.br>.

3 Há que se ressaltar que, no caso do Brasil, a denominação feminista englobava diversos significados; nem todas as mulheres que se diziam feministas, ou eram assim designadas, compartilhavam das mesmas ideias; existiam nuances que as diferenciavam entre si e perante a sociedade. Para uma caracterização desses movimentos no país ver: Besse, 1999; Costa, 2004; Hahner, 2003; Soihet, 2000.
} 
Ao longo das décadas de 1930 e 1940, o debate em torno da questão feminina despertou comentários apaixonados tanto dos defensores de uma maior emancipação feminina, quanto daqueles que repudiavam a crescente presença das mulheres no espaço público. $\mathrm{O}$ tom das discussões era muito diversificado, indo da galhofa mais irreverente até a mais séria argumentação científica, transitando entre as justificativas religiosas, a lógica jurídica $e$ as motivações econômicas. Traçaremos, a seguir, um panorama dos pontos de vista com que nos deparamos, de modo a explicitar em torno de quais assuntos se concentrava a discussão sobre o papel das mulheres na sociedade. Após a realização desse apanhado passaremos para a análise das posturas oficiais, avaliando quais posicionamentos prevaleceram no âmbito do Estado e como eles estavam em consonância com os reclamos de parte da sociedade, evidenciando como, nesse período, as mulheres entraram na pauta das discussões políticas, como elemento significativo para se pensar a formação da população brasileira.

\section{“A mulher" como presença discursiva imposta às mulheres}

Discorrer sobre as mulheres, enumerar suas qualidades $e$ defeitos, tecer hipóteses sobre sua capacidade intelectual, esconjurar sua vida desregrada ou tecer loas à sua virtude angelical era assunto dos mais frequentados, merecendo artigos em jornais, inspirando versinhos em revistas da moda $e$ motivando ensaios em livros. As opiniões emitidas a respeito das mulheres apresentavam matizes diversos, mas o que mais impressiona nesse quadro de discussões é a sua abrangência, o fato de que tudo que se relacionasse às mulheres (aparência, ocupação, comportamento) merecia palavras de louvor ou desdém, configurando-se uma espécie de tribunal social que se encarregava de julgar a conveniência, ou não, de qualquer ato proveniente das mulheres. As argumentações seguiam as mais variadas direções, mas, geralmente, prevalecia a preocupação comum com as possíveis consequências sociais da liberalização 
A questão feminina...

dos costumes e da crescente participação feminina na esfera pública, suscitando ponderações que acabavam por interligar, de alguma forma, o estilo de vida assumido pelas mulheres com os destinos da sociedade e da nação.

As transformações que atingiam a tradicional partilha entre as "coisas de homem" $e$ as "coisas de mulher" provocavam reações distintas. Dentre as mais extremas encontramos aquelas enunciadas por articulistas que apresentavam seus pontos de vista de modo contundente, tecendo comentários que desqualificavam as mulheres de diversas formas: "Na escala zoológica o animal que mais se aproxima da mulher é a barata..."; "Depois do macaco o animal que mais se parece com o homem é a mulher..." (Careta, 01/11/1930:18). Outros emitiam opiniões ainda mais incisivas a respeito do "ordinarismo passional das mulheres", que estariam "descendo a papéis inenarráveis", oferecendo "espetáculos de arrepiar e de confranger", sendo lógico concluir que "Está por natureza absolvido o homem que mata uma mulher... Há no gesto do assassino uma vingança profundamente social. É uma punição positiva de um crime qualquer" (Careta, 13/12/1930:36). Mesmo levando em conta o tom jocoso de algumas dessas colocações, entendemos que a divulgação recorrente desse tipo de fala em certas publicações indica a existência de um ambiente tolerante a práticas de diminuição social das mulheres, principalmente daquelas que não se adequavam aos estereótipos da moça recatada e da esposa/mãe dedicada.

Os alarmistas prognosticavam o fim da paz doméstica caso as mulheres insistissem em conduzir atividades fora do lar ou, até mesmo, adquirissem algum tipo de instrução superior: "A mulher doutora causa-me horror... A mulher douta e um homem douto, reunidos podem formar uma academia, mas não formam um lar perfeito" (Jornal do Brasil, 17/08/1932:5). Os discursos mais virulentos contra a mulher estavam associados ao temor de que a crescente participação feminina no mundo público acabasse por 
estimular outras liberdades, principalmente no campo sexual; alertavam que se deixassem as

\begin{abstract}
mulheres entregues às suas próprias inclinações, aos seus gostos e à liberdade de escolha, o mundo estaria povoado de híbridos, de gente sem raça, sem sangue, sem caráter, monstros gerados ninguém sabe como nem onde (Careta, 20/12/1930:20).
\end{abstract}

Interessante notar que as mudanças no comportamento feminino causavam tamanha comoção que alguns chegavam a defender a legalização do divórcio no Brasil como forma de expurgar a família, livrando-a da presença daquela mulher "que não faz da sua alma o ponto de apoio para a felicidade do homem", esse "aborto da Natureza, um motivo de escândalo, um elemento nocivo para a sociedade que é mister desaparecer". A liberalização feminina estaria levando as mulheres a chafurdar "na poeira das ruas, nos cabarés"; assim, se "O feminismo é o sangradouro por onde o pundonor da mulher se esvai" era preciso reconhecer que, para aquelas que com ele mancomunavam "A ruptura é inevitável e para esses extremos havemos de ter um remédio único - o divórcio" (Coutinho, 1936:81, 91, 96).

Raros eram aqueles que corroboravam tal solução, dado que a tradição católica na qual se apoiava grande parte da sociedade brasileira repudiava, violentamente, o divórcio. Aliás, os posicionamentos da Igreja Católica eram um porto seguro para todos aqueles que desejavam afirmar a necessidade de se manter as mulheres no espaço da casa, concentrada no cuidado dos seus. A Igreja se colocava na linha de frente de qualquer debate sobre a família e o papel das mulheres na sociedade. Com o apoio de uma aguerrida militância leiga, o clero lutava pela primazia da educação religiosa, defendendo que somente a partir da regeneração moral da sociedade brasileira, e da "recatolicização" do país, se lograria derrotar o comunismo e mitigar o liberalismo desenfreado, tidos como expoentes de um materialismo ateu. 
A questão feminina...

As posições da Igreja eram divulgadas nos mais variados veículos de comunicação, mas era através da revista católica $A$ Ordem que seus apoiadores detalhavam os fundamentos das convicções religiosas a respeito da família e das mulheres. Era ponto pacífico entre os articulistas da revista que a principal motivação da existência feminina era a maternidade; o controle da natalidade era tido como nefasto, não somente por impedir, de modo antinatural, a concepção da vida, como também por promover a desocupação das mulheres que, livres dos encargos maternais, poderiam gastar seu tempo em ocupações levianas: "A futilidade feminina dificilmente reina no cérebro daquela que é boa mãe"; era preciso incutir nas jovens a noção de que "A fecundidade é o normal, a mulher infecunda, esta é que está positivamente doente" (A Ordem, 01/1934:47, 53).

Os membros da Igreja ${ }^{4}$ e seus apoiadores estavam cientes de que estavam vivenciando um tempo de transformações, com a introdução de novos comportamentos e ideias que tendiam a amenizar a rigidez das condutas familiares e das relações homemmulher. Se o convencimento a partir do púlpito, as admoestações nas prédicas, não tinham o alcance desejado, era preciso promover a aproximação da Igreja com uma força mais poderosa, o Estado, agente capaz de transformar em lei, e em políticas públicas, aquilo que o clero considerava o único caminho possível para a salvação da "pessoa humana". Apesar de a Igreja ter, inicialmente, apresentado restrições à chamada Revolução de 1930, por tratar-se de um rompimento da ordem instituída, em pouco tempo seus integrantes passaram a reconhecer a legitimidade do governo Vargas, mediante a formação de uma aliança de conveniência entre a Igreja e o Estado, na qual as duas instituições se apoiavam mutuamente (Lenharo, 1986).

\footnotetext{
4 A Igreja Católica exerceu grande influência no meio político brasileiro entre os anos de 1930 e 1945, conseguindo ampla penetração nos diversos escalões do Estado (Miceli, 1979:163). É preciso recordar que, em 1940, 95\% dos brasileiros eram católicos (IBGE, 2007:48).
} 
Dentro das convicções do clero, a hierarquia tinha importância fundamental; a confusão de papéis sociais traria a desestabilização mundana, abrindo o flanco para a disseminação das temidas ideias comunistas. As distinções humanas eram naturais, "Há um modo de ser masculino e outro feminino; há uma vida de adulto e outra de criança; há uma diferenciação natural entre as várias classes sociais" (Lima, 1938:201-202). A Igreja incentivava a via do cooperativismo como modelo de organização social, assentada na colaboração mútua dos diferentes setores, subordinados ao Estado. Contudo, a preeminência estatal tinha limites, fundados, é claro, nos princípios defendidos pela Igreja. Assim, "O Estado não pode alterar a ordem natural de autoridade no âmbito da família [...] estendendo os limites da autonomia conjugal feminina", caberia aos governantes o dever de "impedir tudo o que seja contrário à fecundidade e estimular tudo o que a favoreça" (A Ordem, 11/1940:379, 390, 391).

Interessante notar que, apesar de aparente semelhança nos posicionamentos daqueles que defendiam a manutenção dos papéis "tradicionais" das mulheres, existiam diferenças irreconciliáveis quando se tratava de definir os instrumentos que viabilizariam tal objetivo. Alguns propunham a legalização do divórcio, banindo do seio familiar as mulheres indecorosas; os militantes católicos propunham a conversão espiritual de toda a sociedade, mediada pela Igreja; mas existiam aqueles que renegavam a intervenção das autoridades religiosas no encaminhamento das mulheres, revelando alinhamento com ideias positivistas. ${ }^{5}$ Para estes "É somente da mulher que podemos

\footnotetext{
${ }^{5}$ De acordo com José Murilo de Carvalho (1990:76-100), Auguste Comte acreditava na ação regeneradora da mulher na sociedade, como guardiã do lar, esposa e mãe altruísta. Os seguidores da doutrina positivista no Brasil, mesmo com diferenciações internas, exaltavam a mulher, tida como esteio do ordenamento social. Os positivistas defendiam a separação entre os assuntos do Estado e os interesses da Igreja Católica, considerando que sua doutrina era um obstáculo para o desenvolvimento científico e o progresso das nações.
} 
A questão feminina...

esperar a regeneração da humanidade. Enquanto a mulher brasileira se apegar a santinhas [...] viver mais nas sacristias [...] não podemos esperar dias felizes para o Brasil". A população feminina precisava ser educada para a vida no lar, mas dentro de "princípios racionais e científicos [...] desembaraçada completamente de dogmas e disciplinas padrescos" (Thompson, 1934:234-235).

A grande questão era: como conciliar a noção de que as mulheres, com sua presença no espaço doméstico, eram imprescindíveis para a multiplicação dos brasileiros e para $o$ aprimoramento físico e moral da população, com a crescente participação feminina no mundo público? Muitos consideravam que não era possível acomodar essas duas realidades, sendo necessário manter as mulheres no lar; outros viam como inevitável o ingresso da população feminina no mercado de trabalho e em outras atividades públicas, restando à sociedade o dever de restringir, vigiar e regulamentar esse movimento. A condição materna, principalmente, amainava a "culpa" das mulheres que porventura fossem obrigadas a trabalhar fora de casa em razão de sua precária situação econômica, pois, nesses casos, a mulher estava correspondendo ao ideal de sacrifício tido como inerente ao ser feminino. As operárias eram "abnegadas e heroínas que se esfalfam nas fábricas e oficinas para suprir os parcos recursos do lar", merecendo ser amparadas pelo poder público, desde que se respeitasse a máxima de que "A mulher foi, é, ou deve ser mãe [...] qualquer função, qualquer emprego, qualquer atividade que a mulher exerça é apenas um derivativo de sua função maternal" (Ramos, 1937:66, 83).

Fica evidente que se existiam tantas reações contrárias à presença feminina no mundo público, seja no mercado de trabalho ou em locais de sociabilidade, era porque, de fato, elas estavam alcançando uma posição cada vez mais proeminente na sociedade brasileira, a despeito dos protestos daqueles que consideravam a exposição das mulheres fora do lar como algo impensável. Mesmo diante desse cenário de transformações é 
importante destacar que os valores fundados na precedência da autoridade masculina, na honra familiar auferida através do comportamento das mulheres, dentre outros elementos, ainda constituíam um imperativo poderoso, estabelecendo limites para a conduta das mulheres de "boa família". Era através da função materna que as mulheres poderiam agir como formadoras $e$ regeneradoras do homem, do cidadão e da sociedade, cumprindo o seguinte destino: "nasceu para amar $e$, integrando-se na partícula universal, diluindo-se no todo, assegurar a continuidade do mundo e a perpetuação da espécie" (Ramos, 1937:83).

Das mulheres, de sua disponibilidade para a reprodução $e$ para o cuidado físico e moral dos brasileiros, dependia o futuro do Brasil, "País novo, necessitamos do aumento da população a fim de que cada vez consolidemos mais a posse do território" (Mensário do Jornal do Comércio, 05/1938:561). Para que as mulheres pudessem dedicar-se, com desvelo, às ocupações domésticas, e ao dever de gestar um número cada vez maior de cidadãos, urgia restringir o trabalho feminino fora da casa; por "razões de ordem biológicas e fisiológicas [...] antes que quaisquer razões de ordem social [...] é o interesse da sociedade, pela preservação da raça, que seria seriamente comprometida, se se consentisse um trabalho excessivo" (Ramos, 1937:29, 65). Em contrapartida, era preciso valorizar as mulheres que se dedicavam ao cuidado dos filhos: "Cultuemos a maternidade, tal e tanto como ela merece. Reverenciemos nela o espírito de sacrifício [...] dos sofrimentos, tão necessários à propagação da espécie" (Jornal do Brasil, 09/05/1937:11).

É importante destacar que quando os diversos grupos sociais clamavam pela necessidade da manutenção das mulheres no ambiente do lar, desempenhando as "tradicionais" funções femininas, principalmente no que refere ao exercício da maternidade, isso não implicava no repúdio a mudanças na forma como esses papéis eram vivenciados no seu cotidiano. Pelo contrário, na palavra de médicos e educadores, balizada pela autoridade de um discurso científico que se fortalecia desde a 
A questão feminina...

década de 1920, era preciso modernizar o modo como as mães cuidavam dos filhos e da casa. As mães precisavam ser educadas dentro de parâmetros diferenciados, que permitissem a absorção dos avanços científicos nos campos da higiene, nutrição $e$ pedagogia infantil. Assim, papéis "tradicionais" deveriam ser desempenhados de forma "moderna", alijando práticas tidas como atrasadas e nocivas à criação dos filhos, como: o uso de amas de leite, o desmame precoce do bebê, o uso de remédios caseiros sem o aval de um médico, etc. Nesse contexto de valorização pública do papel materno (entendido em sentido amplo, como a vocação feminina de cuidar do outro), muitas mulheres instrumentalizaram o discurso do "maternalismo" como forma de reivindicar direitos e afirmar seu valor social e político (Freire, 2008:160-162,168). ${ }^{6}$

Era ponto pacífico que sem a contribuição das mulheres, seu envolvimento absoluto na azáfama do lar, não seria possível formar uma população numerosa, imbuída de sólidos princípios morais e cívicos; tampouco seria viável forjar crianças saudáveis, higienizar os ambientes, ministrar cuidados apropriados aos idosos e doentes, tarefas que poderiam, sim, contar com a orientação de médicos e assistentes sociais, mas que fracassariam caso não tivessem continuidade no espaço doméstico, reino por excelência das mulheres. Acreditamos que a forte reação ao quadro de mudanças que se processava na sociedade brasileira nas décadas de 1930 e 1940, particularmente no que se refere às novas possibilidades de vida entreabertas às mulheres, apontava para o fortalecimento da família e do papel das mulheres como donas-decasa e mães. Contudo, essa reafirmação do lugar e das funções apropriadas ao ser feminino apresentava uma nova perspectiva; cuidar do lar, desempenhar a atividade materna, zelar pelo bem estar do outro, constituíam atividades que beneficiavam mais do

\footnotetext{
6 Para um panorama sobre a importância do discurso científico na primeira metade do século XX no Brasil, como forma de educar as mães e a população em geral, ver: Brites, 2000; Duarte, 2004; Martins, 2008.
} 
que apenas a parentela próxima, sendo redimensionadas no quadro social e político como atribuições essenciais para a construção de uma população brasileira vigorosa, disciplinada $e$ apta para o trabalho.

As mulheres brasileiras, principalmente as que residiam nas cidades, vivenciaram as inúmeras mudanças que se processavam no país de forma conflitante, pois ao mesmo tempo em que eram chamadas a participar dessa sociedade que, em vários aspectos, se reinventava, elas também eram pressionadas a permanecer no espaço privado, ocupando-se com os cuidados do lar e da família. Tal quadro se afigurava ainda mais complexo em razão da crescente preocupação com relação ao impacto e à influência que o papel desempenhado pelas mulheres poderia ter na formação da população. O Homem Brasileiro era considerado um ser fraco, subnutrido, ignorante das mais simples medidas de higiene, habitando moradias insalubres que promoviam o desenvolvimento de doenças e que facilitavam a disseminação de vícios e "perversões" (alcoolismo, prostituição, malandragem, banditismo, etc.). Apontava-se como causa dessa situação, não apenas a penúria econômica, mas também moral, em que vivia a classe popular. Para parte expressiva da elite nacional, a solução de tais problemas passava pela melhoria das condições de saneamento básico e ampliação de programas de saúde pública, além da moralização dos costumes nacionais através da manutenção da mulher no espaço doméstico.

A população passou a ser considerada elemento chave para o desenvolvimento do país, de modo que era preciso não apenas reprimi-la, evitando conflitos que desafiassem a ordem instituída, mas também contentá-la, elevar seu nível de bem estar, torná-la útil, através da melhoria das suas condições de vida. Para a formação de um brasileiro de novo tipo, a mulher, principalmente a mãe, precisava receber uma atenção especial, pois a ela caberia, segundo a distribuição ideal de papéis sociais da época, aplicar, no espaço doméstico, os modernos conhecimentos médicos e higiênicos, e também cuidar da formação moral das crianças, 
A questão feminina...

futuros cidadãos do país. Assim, os reclamos daqueles que se insurgiam contra as novas liberdades femininas, defendendo a permanência das mulheres no lar, encontraram guarita não somente entre os segmentos mais conservadores da sociedade, como os católicos militantes, mas também entre cientistas, políticos, educadores, demógrafos, médicos, economistas, que, para além das motivações de cunho moral, pugnavam pela revalorização dos papéis "tradicionais" das mulheres em razão da sua importância estratégica para a constituição de uma população hígida, pedra angular que sustentaria o crescimento econômico do país. Para agir sobre as condições de vida dos brasileiros, principalmente daqueles que habitavam o meio urbano, era necessário redimensionar, dentre outros fatores, o valor das mulheres na sociedade, não tanto de forma a modificar seu campo de atuação, o lar, mas sim de modo a expandir, $e$ aprimorar, suas habilidades no desempenho daquelas atividades corriqueiras às quais elas já se dedicavam há muito tempo. ${ }^{7}$

\section{Quando "ser mulher" se transforma em uma questão de Estado}

Incitar, desenvolver e prolongar a vida dos brasileiros; como regular os fenômenos físicos, biológicos, que constituíam a população? Eram muitas as variáveis a considerar, como: crescimento demográfico, densidade habitacional, condições de higiene, situação nutricional, incidência de doenças e epidemias, mortalidade infantil e salubridade das habitações. Se o Estado não

7 Reprodução, morte, saúde, longevidade, gestação, doenças, alimentação; toda essa vasta gama de dados remete à vida, compreendida no seu aspecto biológico, concreto, configurando um conjunto de elementos relacionados àquilo que Foucault (2004b:3) definiu como biopoder: "essa série de fenômenos [...] a saber, o conjunto de mecanismos através dos quais, aquilo que na espécie humana constitui seus traços biológicos fundamentais, vai poder entrar no interior de uma política, de uma estratégia política, de uma estratégia geral de poder; dito de outro modo, como a sociedade, as sociedades ocidentais modernas, a partir do século XVIII, levaram em conta o fato biológico fundamental que o ser humano constitui uma espécie humana" (tradução nossa). 
interferisse minimamente nessas questões, melhorando a existência cotidiana de pelo menos uma parte da população, seria impossível incrementar a economia do país, que, inserida no contexto internacional da crise de 1929, precisava formar uma massa trabalhadora competitiva $e$ um mercado consumidor interno aquecido.

O Estado, ocupado após a Revolução de 1930 por uma maior diversidade de grupos sociais, começou a agir como operador das principais reivindicações, dos planos e das ideias que pululavam nos meios intelectual e político brasileiros desde a primeira década do século XX. O governo de Getúlio Vargas procurou contentar não somente os segmentos sociais de grande peso político e poder econômico (oligarquias, industriais, militares, Igreja Católica), como também se esforçou para angariar o aval de cientistas, profissionais liberais e intelectuais, convidando-os a integrar a máquina estatal. Essa permeabilidade do governo aos apelos e propostas de parte da sociedade não poderia deixar de ocorrer, também, com relação às discussões em torno da questão feminina, assunto que mobilizava diversos segmentos sociais.

A partir de discursos, ensaios e artigos divulgados em publicações oficiais, além de regulamentações e decretos, poderemos auferir até que ponto o Estado encampou alguns dos posicionamentos que circulavam pela sociedade a respeito do papel que deveria ser desempenhado pelas mulheres. Acreditamos que a ação estatal veio para organizar demandas que já eram expressas por vários setores da sociedade, contemporizando posturas dissonantes e implementando medidas de acordo com seu grau de aceitação entre os segmentos sociais mais influentes. Veremos, a seguir, como as falas emitidas a partir dos espaços institucionalizados se ajustavam, grosso modo, aos discursos que analisamos anteriormente, revelando uma ressonância entre as posturas oficiais e aqueles discursos que se afiguravam como mais comuns na grande imprensa e nos livros da época.

$\mathrm{O}$ ano de 1932 foi, certamente, um marco para as mulheres brasileiras, que conquistaram diversos direitos, tanto políticos, 
A questão feminina...

quanto sociais. O Código Eleitoral estipulou o direito de voto para as mulheres e diversos decretos introduziram avanços inegáveis na legislação trabalhista, favorecendo a população feminina que laborava na indústria e no comércio: concessão do direito à licença-maternidade; proibição do trabalho da mulher grávida durante quatro semanas antes e após o parto; direito da mulher em período de aleitamento a descansos diários, ao longo de seis meses depois do parto; direito a repouso de duas semanas caso a gestante sofresse aborto natural; proibição do trabalho feminino em subterrâneos $e$ outras atividades perigosas $e$ insalubres; igualdade salarial para ambos os sexos, desde que no desempenho das mesmas funções; proibição do trabalho noturno às mulheres, entre dez da noite e cinco da manhã (Decreto $n^{\circ}$ 21.417A, 17/05/1932). Os benefícios de algumas dessas medidas são inegáveis, e muitas dessas conquistas se deveram à luta incansável das trabalhadoras em prol de uma vida mais digna, na qual não vigorasse a exploração desumana a que eram submetidas no ambiente das fábricas $e$ dos estabelecimentos comerciais.

Contudo, se nesse momento a pressão dos movimentos operários foi determinante para a implantação de uma legislação trabalhista nacional, não podemos deixar de atentar para o fato de que também existia, entre diversos segmentos sociais e dentro do próprio Estado, uma preocupação crescente com as condições de vida dos brasileiros, principalmente daqueles que residiam no meio urbano. Afinal, como construir uma nação moderna, desenvolvida economicamente e civilizada, se o país contava com uma massa populacional brutalizada, enferma, explorada ao máximo pelo patronato e fragilizada pela desnutrição? Uma das maneiras de acelerar o processo de transformação do homem brasileiro era amparando as mulheres, impedindo que o trabalho fora de casa as alijasse do cuidado dos filhos e dos afazeres domésticos, permitindo que dividissem o seu tempo de tal forma que as obrigações do emprego pudessem ser conciliadas com o cuidado do lar, evitando o esgotamento de sua energia física após 
um dia de labuta, de modo que ainda suportassem os encargos das gestações, da amamentação, do parto, da criação dos filhos e da faina do lar.

Vejamos, então, como algumas das medidas de proteção às mulheres revelavam uma intencionalidade que ultrapassava o mero desejo de consolidar a presença da população feminina no mundo do trabalho. A proibição do trabalho noturno às mulheres, e também em atividades consideradas insalubres ou perigosas, significava, na prática, estabelecer uma reserva de mercado aos homens, muitos dos quais clamavam pela restrição do emprego feminino, de modo a que estas não ocupassem vagas que pertenceriam aos chefes de família (Wolfe, 1994). Além desse aspecto, a medida possuía um cunho moralizante, dado que a presença feminina nas ruas, após o por do sol, poderia dar margem a certas liberdades, principalmente no campo sexual. $\mathrm{Na}$ prática, a proibição do trabalho noturno significou a demissão de um grande número de mulheres, principalmente em bares $e$ restaurantes. Em 1933, garçonetes protestavam contra a perda dos seus empregos, alegando que a medida implantada configurava um "falso protecionismo" (Hahner, 2003:345). A proibição do exercício de atividades insalubres e perigosas às mulheres só se justificava pelo desejo de preservar seus corpos para a função gestacional, dado que não poderia haver outra explicação para os homens serem autorizados a exercer funções vedadas à população feminina, abrangendo empregos que lidassem com: perigo de acidentes e de envenenamento, necessidade de trabalho atento $e$ prudente, poeira e vapores nocivos (Anexo ao Decreto n. 21.417A, 17/05/1932). Os agentes do Estado deixavam claro que o objetivo das restrições ao trabalho das mulheres era "conservar a sua constituição física e desempenhar, com eficiência, a sua função natural na família, permanecendo mais tempo em seu lar" (Cultura Política, 09/1942:37).

Já a paridade salarial estabelecida para homens e mulheres que exercessem funções idênticas, provavelmente, gerou protestos entre patrões, acostumados a remunerar mal as mulheres, e entre 
A questão feminina...

alguns trabalhadores, que se sentiam diminuídos por receberem o mesmo montante pago a suas colegas. Um decreto-lei de 1940 resolveu a situação, prevendo que

Para os trabalhadores adultos do sexo feminino, o salário mínimo, respeitada a igualdade com que vigorar no local, para o trabalhador adulto do sexo masculino, poderá ser reduzido em 10\% (Decreto lei n. 2.548, 31/08/1940, art. $2^{\circ}$ ).

Assim, as medidas que, concretamente, mais beneficiaram as mulheres trabalhadoras foram justamente aquelas concernentes à sua condição materna, que resguardavam a gravidez, o parto e o aleitamento, funções que garantiam a sobrevivência de um maior número de crianças, e a preservação da saúde da mãe para que pudessem cuidar dos filhos e recuperar-se fisicamente para futuras gestações. Não se trata de diminuir a importância histórica dessas conquistas, que, quando aplicadas, melhoraram sensivelmente a existência das mães trabalhadoras. Desejamos, sim, pontuar como essas novas prerrogativas coincidiam com o despertar de uma visão diferenciada sobre a importância das mulheres para a constituição da população, de modo que protegê-las em sua condição materna adquiria sentidos que ultrapassavam a perspectiva individual $e$ de classe, constituindo-se em medida governamental que já levava em conta seu alcance massivo, possível impacto na configuração populacional. ${ }^{8}$ Tratava-se de

8 Segundo Foucault (2004b:72-74), "De fato, a população não é um dado primário, ela está na dependência de toda uma série de variáveis. A população vai variar com o clima. Ela vai variar de acordo com o ambiente material; a intensidade do comércio [...] de acordo com as leis a que está submetida, por exemplo, os impostos, as leis sobre o casamento". A partir da segunda metade do século XVIII toma forma a ideia de que "levando em conta esses fatores será possível, efetivamente, agir sobre a população. Desenha-se, então, uma técnica totalmente diferente [...] levar em conta elementos aparentemente distantes da população, mas que se sabe, através do cálculo, da análise e da reflexão, que eles podem, efetivamente, agir sobre ela. É essa naturalidade penetrável da população que levará, eu acredito, a uma mutação muito importante na organização e racionalização dos métodos de poder" (tradução nossa). 
uma faceta do poder que buscava não reprimir, e sim incitar, produzir, criar novas práticas, incentivar certas condutas, modos de agir e comportamentos; sua eficácia residia, não na ação destrutiva, mas na sua capacidade de criação. No caso das mulheres, esse poder benfazejo fomentava a percepção de que a maternidade poderia ser experimentada de modo ainda mais positivo, no sentido de que traria, para aquelas que trabalhavam fora do lar, alguma proteção, benefícios práticos que promoveriam a vivência cada vez mais plena do papel maternal.

No mais das vezes, o trabalho feminino fora do lar, desde que motivado por necessidade econômica, era encarado com resignação. Melhor seria se as mulheres fossem exclusivamente donas de casa, mas, como esse ideal se afigurava inalcançável, cabia ao Estado

\begin{abstract}
amparar, uma vez que é impossível impedir que a mulher trabalhe [...] Seria agradável se se pudesse riscar do vocabulário humano a palavra operária [...] como é impossível, resta aos governos [...] minorar o sofrimento (Cultura Política, 09/1942:36-37).
\end{abstract}

Essa visão pragmática era comum nos discursos oficiais, e as medidas de proteção às trabalhadoras eram louvadas por resguardar a capacidade reprodutiva das brasileiras, afinal "Só uma raça física e culturalmente forte é capaz de aguentar com os imprevistos do amanhã. Precisamos de mães sadias e robustas, que garantam gestações perfeitas e filhos normais", era preciso considerar que "O problema da Maternidade é eugênico, demográfico, higiênico, de defesa social, de progresso econômico, moral e cultural, devendo ser dirigido em razão da procriação perfeita e sem restrições" (Ciência Política, 07/1944:37, 42).

De acordo com o Ministro do Trabalho, Marcondes Filho (1943:51-54), a mulher trabalhadora deveria gozar de direitos, não porque labutasse tão duramente quanto os homens, mas sim "porque é da classe operária que provem o maior número de 
A questão feminina...

cidadãos". Antes da legislação trabalhista destinada à proteção das mulheres, elas eram "mal dormidas, sem nutrição sadia, vencidas pelo cansaço", e seus "filhos nasciam raquíticos" (id.ib.). Certamente que esse modo de se referir às operárias, apresentando-as como figuras indefesas e frágeis, escamoteava, convenientemente, sua tradição de luta, e o fato de que os benefícios que gozavam foram alcançados em razão, dentre outros fatores, da pressão organizada que exerceram sobre os empregadores e o Estado. Contudo, a tentativa deliberada de despolitizar a conquista dos direitos sociais através da evocação dessas cenas não era incompatível com outras intencionalidades, $e$ as regras de amparo às trabalhadoras adquiriam sentidos diversos, sendo comum, entre os agentes estatais, a noção de que com a nova legislação protetora as mulheres não seriam mais "obrigadas a renunciar aos deveres da maternidade, com sacrifício de sua saúde e dos interesses da coletividade nacional" (Ciência Política, dez./jan. 1940:55).

Assim, o Estado procurou estabelecer medidas de proteção, $e$ de restrição, ao trabalho feminino, admitindo como inevitável que muitas mulheres fossem obrigadas a buscar o sustento fora do lar, mas garantindo, ao mesmo tempo, que esse trânsito se desse de forma moralizada, sem prejudicar suas obrigações domésticas e sua função reprodutiva. Em que pese a importância atribuída ao mundo do trabalho, a preservação do papel "tradicional" das mulheres dependia de outras realizações, que deveriam ir além da mera regulamentação, e restrição, do emprego feminino. Se a intenção era formar uma população nacional mais ativa $e$ saudável era preciso agir sobre a unidade familiar, torná-la campo de ação das medidas intervencionistas que, se multiplicadas em cada lar, espaço micro, não deixariam de produzir efeito em grande escala, resultando em transformações substanciais no quadro populacional do Brasil, e em outras instâncias interligadas, como a econômica. Uma das obsessões dos agentes governamentais era quanto ao nível de crescimento da população brasileira; muitos consideravam o número de nascimentos baixo, $e$ 
afirmavam que, caso não houvesse incentivos nessa área, o país logo sofreria, não só escassez de mão de obra, como um desequilíbrio ainda maior entre as regiões densamente habitadas e aquelas menos populosas.

Em abril de 1941, foi instituído o decreto-lei 3.200, que dispunha "sobre a organização e proteção da família". O dispositivo legal procurou incentivar os casamentos e facilitar a formalização das uniões, conferindo efeitos civis ao casamento religioso e estabelecendo a gratuidade do casamento civil para os nubentes pobres. Autorizou, ainda, a concessão de empréstimos para a aquisição de moradia familiar àqueles que pretendiam casar-se, sendo requisito para adquirir o benefício que os pretendentes se submetessem a um exame médico capaz de atestar a saúde do casal. Fica evidente a intenção do governo em incentivar, não somente o casamento legal, como o incremento da taxa de natalidade através da concessão de benefícios aos casais mais fecundos, já que a lei previa que, no caso desses empréstimos:

Por motivo do nascimento de cada filho do casal, mediante apresentação da certidão do respectivo registro $e$ atestado de saúde [...] se fará no mútuo dedução da importância correspondente a dez por cento da importância inicialmente devida, ou redução de dez por cento da amortização mensal, como preferir o mutuário. Quando cada filho completar dez anos de idade, o mutuário, provando que lhe presta a assistência devida, educando-o convenientemente, obterá nova redução [...] (Decreto-lei 3.200, art. $8^{\circ}, \S 7^{\circ}$ ).

No caso de empréstimos para pessoas já casadas, "Quando concorrerem vários pretendentes aos mútuos [...] serão preferidos os casados que tenham filho, e, dentre os casados, os de prole mais numerosa" (id.ib., art. 12). Apesar de todos esses dispositivos terem agradado a Igreja Católica, que acompanhou de perto a elaboração da lei, houve uma seção que foi recebida com desagrado pelos clérigos e militantes católicos; tratava-se do 
A questão feminina...

capítulo VII, que previa o reconhecimento dos filhos naturais ("ilegítimos"), atribuindo-lhes os mesmos direitos arrogados aos filhos concebidos dentro do casamento. Tal fato demonstra que a lei, apesar de possuir caráter moralizante, não deixou de ter em vista um propósito maior, perseguido por homens do governo $e$ apoiado por categorias profissionais prestigiadas no momento, como médicos, demógrafos e pedagogos, segundo o qual importava mais para o país a constituição de uma população numerosa e saudável. A distinção legal entre filhos nascidos dentro e fora do casamento estabelecia a existência de brasileiros de segunda classe, sem direito a assistência completa dos progenitores, prejudicando a formação desses futuros cidadãos, dos quais a nação não poderia prescindir. Os princípios morais $e$ religiosos eram tidos como fundamentais, e sempre que compatíveis com as novas diretrizes de preservação $e$ incremento da vida receberiam o apoio do Estado, mas não teriam precedência caso colidissem com o projeto de melhoria do todo populacional.

O decreto-lei estabeleceu, ainda, que, respeitando os demais requisitos para a contratação, teria "preferência, para nomeação para cargo ou admissão como extranumerário, do serviço público federal, estadual ou municipal, e bem assim para promoção [...] o casado com relação ao solteiro", e, "dentre os casados, o que tiver maior número de filhos" (id.ib., art. 26). Quanto às obrigações fiscais, constavam as seguintes disposições:

Os contribuintes do imposto de renda, solteiros ou viúvos sem filho, maiores de vinte e cinco anos, pagarão o adicional de quinze por cento, e os casados, também maiores de vinte e cinco anos, sem filho, pagarão o adicional de dez por cento;

já "os contribuintes do imposto de renda, maiores de quarenta e cinco anos, que tenham um só filho, pagarão o adicional de cinco 
por cento sobre a importância do mesmo imposto" (id.ib., arts. 32, 33). Considerava-se família numerosa aquela constituída por

oito ou mais filhos, brasileiros, até dezoito anos de idade, ou incapazes de trabalhar, vivendo em companhia e a expensas dos pais ou de quem os tenha sob sua guarda criando e educando-os à sua custa (id.ib., arts. 37, 39).

Optamos por citar, detalhadamente, alguns dispositivos da lei, de modo a explicitar a importância capital da questão familiar naquele período. Não resta dúvida de que o Estado se alinhou com as vozes mais influentes da sociedade, atendendo aos reclamos, não somente da Igreja Católica, como também de todos aqueles que, a partir do exercício de suas profissões, pediam a intervenção estatal no sentido de incentivar a procriação, o casamento e a formação de famílias moralizadas e saudáveis. As minúcias da lei procuraram traçar um círculo protetor em torno da instituição familiar, cuidando mais de incentivar do que penalizar os cidadãos; dentro da nova forma de governar inaugurada, o Estado era aquele que incitava, beneficiava e promovia, esperando que, com a instituição de privilégios para os casais mais fecundos, houvesse um crescimento da taxa de natalidade. ${ }^{9}$ Para os solteirões e viúvos empedernidos, e casados pouco prolíferos, restava pagar tributo à nação pelas suas escolhas, mas tal medida visava não tanto encher os cofres do fisco, e sim provocar a capitulação daqueles que resistiam em constituir família ou ter mais filhos. Era através da regulação das relações familiares, portanto, que se pretendia constituir uma população nacional de novo tipo, numerosa, legalizada pelo casamento, saudável e apta para o trabalho; mais do que uma instituição privada, a família passou a ser ponto de ancoragem para as ações estatais, e tudo

9 O censo de 1940 revelou que "as mulheres entre 15 e 49 anos de idade tinham em média 6,2 filhos" (IBGE, 2007:34). Tal percentual certamente não foi considerado satisfatório, pois a lei de 1941 considerou como família numerosa aquela que tivesse oito filhos ou mais. 
A questão feminina...

aquilo que corria na privacidade do lar tornou-se de interesse público em razão do seu efeito potencial sobre a formação da população.

Claro está que para a concretização de todas essas metas seria necessário mobilizar as mulheres, conscientizá-las da importância do seu papel, educá-las quanto aos cuidados que deveriam dispensar às crianças $e$ ao lar. A melhor forma de solucionar a questão, ampliando o acesso a esses ensinamentos, era introduzir, no currículo das escolas, dispositivos que obrigassem as mocinhas a frequentar aulas que as instruíssem sobre a lida doméstica. No corpo da Lei Orgânica do Ensino Secundário, de 1942, estabeleceu-se o seguinte quanto à educação feminina: "É recomendável que a educação secundária das mulheres se faça em estabelecimentos de ensino de exclusiva frequência feminina"; para as alunas a disciplina de economia doméstica seria incluída "na terceira e na quarta série do curso ginasial e em todas as séries dos cursos clássico e científico"; os programas desenvolvidos nas escolas deveriam ter "em mira a natureza da personalidade feminina e bem assim a missão da mulher dentro do lar" (Decreto-lei n. 4.244, 09/04/1942, art. 25).

Assim, o Estado, para administrar esse todo dinâmico e complexo (tendo em vista que inúmeros fenômenos poderiam influenciar na criação desse novo homem brasileiro), passou a governar levando em conta a inter-relação dos vários processos humanos; de modo que as medidas que editava, $e$ as considerações que enunciava por meio dos seus agentes, procuravam atentar para a repercussão de todo e qualquer elemento na configuração do conjunto populacional almejado. É preciso aumentar o número de brasileiros? Então que se instituam abonos salariais para os pais de vasta prole, dê-se preferência no emprego para chefes de família com muitos filhos, liberem-se empréstimos para o casal prolífero, etc. No entrecruzamento de questões aparentemente diversas, o Estado varguista estabeleceu outra maneira de governar, instituindo um poder de caráter relacional: o econômico, por exemplo, que antes era instrumento 
de gestão apenas do mundo financeiro, empresarial, passa a ser, também, mecanismo de regulação da questão reprodutiva, do tipo de família a incentivar. No caso das mulheres, na percepção de que seu comportamento individual também teria implicações na formação do todo populacional, procurou-se induzir, incentivar, a adoção de condutas que, se incorporadas minimamente por um número considerável de mulheres no âmbito familiar, poderia influir na conformação quantitativa e qualitativa da população brasileira, ao menos a urbana.

\section{Considerações finais}

A partir das considerações desenvolvidas, acreditamos que ficou patente a importância atribuída às mulheres ao longo da Era Vargas, em razão de sua ligação explícita e primeira com todos os processos vitais que tanto interesse despertavam nos homens da época. Por essa razão elas se transformaram em alvo privilegiado de medidas educativas e moralizantes que, propagadas no ambiente familiar, ajudariam a constituir uma população de outro tipo, menos ignorante, enferma e indolente, de forma que esse cortejo de miseráveis se convertesse em um conjunto produtivo, capaz de trabalhar e consumir, impulsionando as forças econômicas da nação e promovendo a ordem social. Note-se que, nesse momento, o desejo de formar uma população mais saudável e diligente fortalecia o posicionamento daqueles que desde sempre eram favoráveis à permanência das mulheres no lar, dedicando-se à família e às atividades domésticas. Formou-se, assim, um ambiente propício à disseminação de opiniões conservadoras em relação às mulheres, o que explica, do nosso ponto de vista, o fato de grupos diversificados terem adotado ideias tão semelhantes sobre os papéis a serem desempenhados pela população feminina na sociedade. Cientistas, intelectuais, religiosos, profissionais liberais, homens do Estado, militantes políticos; as motivações e as crenças de cada qual poderiam ser diferentes, mas eles compartilhavam a noção de que o lugar das 
A questão feminina...

mulheres era no lar, exercendo aquelas atribuições que lhe cabiam desde tempos imemoriais.

Não podemos deixar de assinalar que, se parte da sociedade brasileira cerrou fileiras em prol da manutenção das mulheres em suas funções "tradicionais", esse fenômeno também se deveu à crescente emancipação feminina que, paradoxalmente, marcou o período. Os grupos mais conservadores reagiam às transformações culturais que introduziam novos comportamentos e modelos de conduta para as mulheres, repudiando a participação feminina no mercado de trabalho e a conquista de direitos políticos. Não se trata, portanto, de traçar um cenário no qual as mulheres seriam completamente submissas, impotentes e indefesas, ficando à mercê de uma sociedade opressora e autoritária. Os projetos governamentais, as regulamentações e os decretos, restaram, muitas vezes, como letra morta, carecendo de recursos materiais para sua aplicabilidade ou de força política para sua implantação. No caso deste artigo, não nos propomos a analisar a atuação das chamadas feministas, ou das operárias da época. ${ }^{10} \mathrm{~A}$ nossa intenção é refletir sobre a importância atribuída às mulheres nesse período vis-à-vis a questão da população, como elas constituíram um segmento privilegiado dentro de um projeto maior, encampado pelo poder instituído, que objetivava formar brasileiros de novo tipo, capazes de colaborar para a construção de outro Brasil, economicamente poderoso, ordeiro e civilizado.

Nesse sentido, acreditamos que o Estado transformou-se em agente operacional de ideias e propostas que já estavam presentes na sociedade brasileira, a respeito da importância da atuação feminina no âmbito familiar e no espaço doméstico. A partir dessas instâncias, a mulher contribuiria para a construção de cidadãos moralizados e saudáveis, atendendo aos reclamos de segmentos sociais diversos que, por motivações diferentes, pleiteavam uma ação do governo no sentido de proteger

\footnotetext{
${ }^{10}$ Para um panorama sobre as pesquisas desenvolvidas no Brasil sobre gênero, ver Soihet e Pedro (2007:281-300).
} 
a família $e$ as funções femininas "tradicionais". Essas iniciativas governamentais não se traduziriam, necessariamente, apenas em medidas repressoras e proibitivas; mais do que cercear, o Estado incentivava condutas que levassem ao crescimento da taxa de natalidade, beneficiava determinado modelo familiar fundado no casamento formal e na prole numerosa, regulamentava o trabalho feminino de forma a proteger a saúde das mulheres para a função reprodutiva, implementava a obrigatoriedade de uma educação especial para elas, idealizava a figura materna como sustentáculo da nação.

Era preciso exorcizar os "erros" do passado, momento em que os governantes teriam fugido

à realidade das coisas e dos seres, em uma palavra, tendo fugido à vida [...] Ora, não é a vida que deve adaptar-se ao Estado, mas este à vida (Cultura Política, 06/1943:44).

O Estado, renovado pela maior diversidade de segmentos sociais que o ocuparam após a Revolução de 1930, passou a traçar planos, fazer cálculos, instituir metas, objetivando a construção de uma população de novo tipo que, purgada de suas mazelas, fosse capaz de contribuir para o crescimento econômico da nação. Claro está que as medidas implantadas pelo governo Vargas não atingiram a totalidade da população, ficando restritas aos grandes centros urbanos, onde se concentravam operários, fábricas, serviços e comércio em maior escala. Mesmo assim, no que toca à valorização do homem, esse período representou um momento de inflexão na história do Brasil, pois de súcia indisciplinada, malta de ignorantes e preguiçosos, os nacionais passaram a ser considerados como capital, elemento econômico dotado de valor e utilidade, precisando receber investimentos que, traduzidos na melhoria das condições materiais de vida, ajudariam a alavancar a economia do país. Dentro dessa perspectiva, as mulheres também adquiriram especial importância, pois, além de integrarem o todo populacional e o contingente de mão de obra, elas eram as 
A questão feminina...

principais realizadoras de todas as operações constitutivas da saúde dos indivíduos, manipulando e preparando alimentos, mantendo ambientes limpos, zelando pelas crianças, doentes $e$ idosos, sem contar os encargos da gravidez, do parto e do aleitamento. Para melhorar qualquer desses índices vitais era preciso passar pelas mulheres, dedicar-lhes atenção especial, educá-las, protegê-las em suas funções biológicas, incentivar sua permanência no lar, integrando-as dentro de um projeto maior que visava formar uma população de novo tipo, mais civilizada, sã e operosa.

\section{Referências bibliográficas}

ANDERSON, Benedict. Nação e Consciência Nacional. São Paulo, Editora Ática, 1989.

BESSE, Susan K. Modernizando a Desigualdade: reestruturação da ideologia de gênero no Brasil: 1914-1940. São Paulo, Editora da Universidade de São Paulo, 1999.

BRITES, Olga. Infância, higiene e saúde na propaganda (usos e abusos nos anos 30 a 50). Revista Brasileira de História, São Paulo, vol.20, n 39,2000 , pp.249-278.

CARDOSO, Ciro Flamarion; MALERBA, Jurandir. (orgs.) Representações contribuição a um debate transdisciplinar. São Paulo, Papirus, 2000.

CARVAlHo, José Murilo de. A formação das almas: o imaginário da República no Brasil. São Paulo, Companhia das Letras, 1990.

CODATO, Adriano Nervo; GUANDALINI, Walter. Os autores e suas ideias: um estudo sobre a elite intelectual e o discurso político do Estado Novo. Estudos Históricos, Rio de Janeiro, n 32, 2003, pp.145-164.

CostA, Suely Gomes. Movimentos feministas, feminismos. Estudos Feministas, Florianópolis, vol. 12, Set/Dez 2004, pp.23-36.

DUARTE, Regina Horta. Em todos os lares, o conforto moral da ciência e da arte: A Revista Nacional de Educação e a divulgação científica no Brasil (1932-1934). História, Ciências, Saúde - Manguinhos, Rio de Janeiro, vol. 11, n 1, 2004, pp.33-56. 
DuBY, Georges; PerROT, Michelle. (orgs.) História das Mulheres - O século XX. vol. 5. Porto, Edições Afrontamento, 1991.

DUTRA, Eliana de Freitas. O Ardil Totalitário: imaginário político no Brasil dos anos 30. Rio de Janeiro, Editora UFRJ, 1997.

EISENBERG, José. Patriotismo e gênero na tradição do pensamento político moderno: uma genealogia. Revista USP, São Paulo, n 59 , set./nov. 2003, pp.21-35.

FAUSTO, Boris. O pensamento nacionalista autoritário (1920-1940). Rio de Janeiro, Jorge Zahar, 2001.

FouCAUlT, Michel. História da Sexualidade I: a vontade de saber. Rio de Janeiro, Edições Graal, 1985.

. Naissance de la Biopolitique. Cours au Collège de France 1978-1979. Paris, Gallimard/Seuil, 2004.

. Sécurité, territoire, population. Cours au Collège de France. 1977-1978. Paris, Gallimard/Seuil, 2004.

FREIRE, Maria Martha de Luna. 'Ser mãe é uma ciência': mulheres, médicos e a construção da maternidade científica na década de 1920. História, Ciências, Saúde - Manguinhos, Rio de Janeiro, vol. 15, supl., jun. 2008, pp.153-171.

Gomes, Ângela de Castro; OliveIRA, Lúcia Lippi; Velloso, Mônica Pimenta. Estado Novo: ideologia e poder. Rio de Janeiro, Zahar Editores, 1982.

GrossI, Miriam Pillar; PEDRO, Joana Maria. (orgs.) Masculino, feminino, plural: gênero na interdisciplinaridade. Florianópolis, Ed. Mulheres, 1998.

HAHNER, June E. Emancipação do sexo feminino - A luta pelos direitos da Mulher no Brasil, 1850-1940. Florianópolis, Ed. Mulheres/Santa Cruz do Sul, EDUNISC, 2003.

IBGE. Tendências Demográficas - uma análise da população com base nos resultados dos censos demográficos de 1940 e 2000. Coleção Estudos e Pesquisas - Informação geográfica e socioeconômica, $\mathrm{n}^{\circ}$ 20, Rio de Janeiro, 2007.

LenHARO, Alcir. Sacralização da Política. Campinas, SP, Papirus, 1986. 
A questão feminina...

MARIANO, Silvana Aparecida. O sujeito do feminismo e o pósestruturalismo. Revista Estudos Feministas, Florianópolis, vol.13, n 3 , set./dez. 2005. Disponivel em: <www.scielo.br/ref>

MARTINS, Ana Paula Vosne. "Vamos criar seu filho": os médicos puericultores e a pedagogia materna no século XX. História, Ciências, Saúde - Manguinhos, Rio de Janeiro, vol.15, nº1, jan.-mar, 2008, pp.135-154.

MATOS, Maria Izilda Santos de; SOIHET, Rachel. (orgs.) O corpo feminino em debate. São Paulo, Editora UNESP, 2003.

MICELI, Sérgio. Intelectuais e classe dirigente no Brasil (1920-1945). São Paulo/Rio de Janeiro, DIFEL, 1979.

Pandolfi, Dulce. (org.) Repensando o Estado Novo. Rio de Janeiro, Ed. FGV, 1999.

PRIORE, Mary Del. (org.) História das Mulheres no Brasil. São Paulo, Contexto, 2004.

RAGO, Margareth. Do cabaré ao lar: a utopia da cidade disciplinar: Brasil 1890-1930. Rio de Janeiro, Paz e Terra, 1985.

Schwartzman, Simon; Bomeny, Helena Maria Bousquet; COSTA, Vanda Maria Ribeiro. Tempos de Capanema. São Paulo, EDUSP/Paz e Terra, 1984.

SCOTT, Joan. História das Mulheres. In: BuRKE, Peter. (org.) A Escrita da História - Novas perspectivas. São Paulo, UNESP, 1992, pp.63-95.

SOIHET, Rachel. A pedagogia da conquista do espaço público pelas mulheres e a militância feminista de Bertha Lutz. Revista Brasileira de Educação, Rio de Janeiro, Set/Out/Nov/Dez 2000, pp.97-117.

. Violência simbólica - saberes masculinos e representações femininas. Revista Estudos Feministas, Florianópolis, vol.5, $\mathrm{n}^{\circ} 1$, jan./jul.1997, pp.7-29.

SOIHET, Rachel; PEDRO, Joana Maria. A emergência da pesquisa da História das Mulheres e das Relações de Gênero. Revista Brasileira de História, São Paulo, vol. 27, nº 54, 2007, pp.281-300. 
VILHENA, Cynthia. Família, mulher e prole: a doutrina da Igreja e a política social do Estado Novo. Tese de doutorado, Faculdade de Educação, USP, 1988.

WolfE, Joel. "Pai dos pobres" ou "Mãe dos ricos"?: Getúlio Vargas, industriários e construções de classe, sexo e populismo em São Paulo, 1930-1954. Revista Brasileira de História, São Paulo, ANPUH/Marco Zero, vol. 14, n 27,1994 , pp.27-59.

\section{Fontes}

\section{Periódicos}

- A Ordem - RJ

- Careta - RJ

- Ciência Política - RJ

- Cultura Política - RJ

- Jornal do Brasil - RJ

- Mensário do Jornal do Comércio - RJ

\section{Livros}

CoutinHO, Octaviano. O divórcio. Rio de Janeiro, A encadernadora, 1936.

FILHO, Alexandre Marcondes. Trabalhadores do Brasil! - palestras do ministro Marcondes Filho na Hora do Brasil em 1942. Rio de Janeiro, [Revista Judiciária], 1943.

LimA, Alceu Amoroso. Idade, Sexo e Tempo: três aspectos da psicologia humana. Obras Completas de Alceu Amoroso Lima - XXVII.. Rio de Janeiro, Livraria AGIR Editora, 1953 [1ª edição 1938]

RAmOS, Carlos De Oliveira. Da proteção legal ao trabalho das mulheres e dos menores - Da proteção à maternidade no direito operário. Fortaleza, Imprensa Oficial, 1937.

THOMPSON, Arthur (Almirante). O Despertar de uma Nação. Rio de Janeiro, Tipografia Baptista de Souza, 1934. 